\title{
Improving Monitoring and Water Point Functionality in Rural Ethiopia
}

\author{
Carmen Anthonj ${ }^{1, *}$, Lisa Fleming ${ }^{1}$, Ryan Cronk ${ }^{1}\left(\mathbb{D}\right.$, Samuel Godfrey ${ }^{2}$, Argaw Ambelu ${ }^{3}{ }^{(}$, \\ Jane Bevan $^{2}$, Emanuele Sozzi ${ }^{1}$ (D) and Jamie Bartram ${ }^{1}$ (D) \\ 1 Water Institute, Gillings School of Global Public Health, University of North Carolina, Chapel Hill, \\ NC 27599, USA; lisaf@live.unc.edu (L.F.); rcronk@live.unc.edu (R.C.); esozzi@email.unc.edu (E.S.); \\ jbartram@email.unc.edu (J.B.) \\ 2 Water, Sanitation and Hygiene (WASH), UNICEF Ethiopia, P.O. Box 1169, Addis Ababa 1169, Ethiopia; \\ sgodfrey@unicef.org (S.G.); jbevan@unicef.org (J.B.) \\ 3 Department of Environmental Health Sciences \& Technology, Jimma University, P.O. Box 378, Jimma, \\ Ethiopia; aambelu@yahoo.com \\ * Correspondence: carmen.anthonj@unc.edu; Tel.: +1-919-966-7644
}

Received: 24 September 2018; Accepted: 29 October 2018; Published: 7 November 2018

\begin{abstract}
This study examines the patterns, trends, and factors associated with functional community water points in rural Ethiopia and identifies potential areas of improvement in terms of practitioner response to functionality and functionality monitoring. It was part of an integrated $\mathrm{WaSH}$ and nutrition program implemented by UNICEF Ethiopia and the Government of Ethiopia. Cross-sectional surveys were conducted to collect WaSH-related data in communities and WaSH committees from four community-based nutrition (CBN) program groupings in Ethiopia. In all areas, CBN was implemented, but only in less than half of the areas, a WaSH intervention was implemented. Seventy-three representative kebeles, comprising 30 intervention and 43 control communities, were surveyed. Two structured surveys were conducted. The 'community survey' addressed community water points and their functionality and the main areas for improvement needed. The 'WaSH committee survey' investigated technical and management aspects of water points and their functionality. Data were analyzed using bivariate regression to identify community characteristics and management practices associated with functionality of water points and explore opportunities to improve water point functionality and monitoring. In the communities, $65 \%$ of water points were functional. Eighty percent of communities had a WaSH committee. The WaSH committee members reported that the most used water point types were protected dug wells and boreholes, and that $80 \%$ of their water points were functional. India Mark II pumps were more likely to be functional and communities with longer established WaSH committees had higher water point functionality. Communities suggested that the key factors for water point sustainability were improving water quality and water pressure, reducing water collection time, and speeding up repair times. Taking community leaders' 'priority lists' into consideration offers sustainable opportunities for demand-driven, adaptive and targeted design and implementation of rural water supply programs, which, if they include the grassroots level as key informants and actors of change, can succeed. Interventions should integrate the 'voice' of the community, the WaSH committees, and other stakeholders and thereby facilitate transdisciplinary approaches at different stages of program management (planning, monitoring, and evaluation). This would help closing the knowledge to action gap and improve policy, programming, practice, and service delivery.
\end{abstract}

Keywords: community perceptions; drought; handpump; monitoring and evaluation; participation; rural water supply; seasonality; sustainability; transdisciplinarity; WaSH committee; WaSH intervention 


\section{Introduction}

Access to safely managed drinking water and sanitation services and basic hygiene (WaSH) are foundations of human health, well-being, socio-economic development, and human dignity [1-7]. Achieving universal access to safely managed water and sanitation services is a priority in global development policy, reflected in Goal 6 of the Sustainable Development Goals (SDGs).

A safely managed drinking water service is an improved source accessible on premises, available when needed, free from contamination. A basic drinking water service includes drinking water from an improved source, with a collection time of less than $30 \mathrm{~min}$ for a roundtrip including queuing, which despite the global commitment to WaSH, many low- and middle-income countries (LMICs) do not have universal access to [8]. As per definition of the WHO/UNICEF Joint Monitoring Programme (JMP), improved drinking water sources are those which, by nature of their design and construction, have the potential to deliver safe water, and include: piped water, boreholes or tubewells, protected dug wells, protected springs, rainwater, and packaged or delivered water.

The JMP estimates that $30 \%$ of the rural Ethiopian population had access to a basic drinking water service in 2015 [9]. The National Growth and Transformation Plan II's Water and Sanitation [10] targets $83 \%$ of the total population using safely managed, adequate, and resilient water supply services by 2020. Given the numbers provided by the JMP and in a recent publication from the program area [11], there is a long way ahead to achieve this target.

Even where basic water services are available, water points are non-functional (i.e., water unavailable from a water point at the time of survey) $[12,13]$. Measuring water service availability parameters is a challenge due to the complex range of outcomes associated. There are many factors, such as fee collection, access to post-construction support, and management arrangements associated with functional water points that help practitioners identify opportunities to improve service delivery [13-18]. Few studies describe factors associated with functionality and patterns and trends in water point management in Ethiopia.

This study from rural Ethiopia aimed to (i) investigate the patterns, trends, and factors associated with functional community water points and (ii) identify potential areas of improvement in terms of practitioner response to functionality and functionality monitoring.

\section{Methods}

Cross-sectional surveys were conducted in communities and with WaSH committees in Amhara, Oromia, Tigray, and Southern Nations, Nationalities, and Peoples' Region (SSNPR) of Ethiopia. Data were collected between January and March 2017, by the Water Institute at the University of North Carolina (UNC) and Jimma University, on behalf of UNICEF Ethiopia, from four community-based nutrition $(\mathrm{CBN})$ program groupings.

\subsection{Study Context}

In the context of food insecurity and malnutrition, and in order to maximize the potential health impact of community-based nutrition (CBN) programs among vulnerable groups in rural Ethiopia, an integrated nutrition and WaSH program was implemented by UNICEF Ethiopia and the Government of Ethiopia between 2011 and 2015. It was designed to respond to the combined risks of chronic malnutrition and inadequate access to basic WaSH services for 1.4 million people in four regions in rural Ethiopia.

In all surveyed areas, CBN was implemented. In some areas, a WaSH intervention was implemented (community water supply, hygiene promotion and sanitation, multiple use services), whereas in the control group, only CBN was implemented. Thirty intervention woredas (districts) comprising 576 kebeles (communities) were subject to the WaSH intervention. Of these, 15 were food and water insecure, and the other 15 woredas were relatively water secure and received CBN only (methods which are detailed in reference [11]). 


\subsection{Sampling}

Seventy-three representative kebeles, including 30 intervention and 43 control communities, were identified by random sampling. A survey was conducted in each community with members representing the community and knowledgeable about kebele resources including water and sanitation facilities, i.e., community or opinion leaders, religious leaders, elders, community health volunteers, women's affairs leaders.

WaSH committee surveys were conducted in kebeles that had a functional WaSH committee and protected water points. Members of WaSH committees are locally responsible for water point maintenance, establishment of new water points, and management of existing water points. WaSH committees are established by the woreda water office or by the kebele administration. A WaSH committee consists of permanent residents who have the potential to mobilize their community and raise funds, selected by the community members. Half of a WaSH committee is supposed to be male, and half female. The WaSH committee (WaSHCo) has a chairperson, secretary, logistic personnel, and head of finance. It is the WaSHCo's responsibility to collect funds and service fees from community members, aid organizations, and the government. The WaSHCo is directly responsible for contracting, procurement, quality control, and financial accountability to the community, kebele, and woreda administration. The community/kebele has the right to dissolve the committee if they are not functional or transparent. Committee members in charge of administering the water points qualified for participation in the survey.

\subsection{Data Collection}

Data collection was carried out by 21 field enumerators and four supervisors recruited by Jimma University and trained by Jimma University, the Water Institute at UNC, and UNICEF Ethiopia. Surveys were conducted using separate survey tools for community members and WaSHCo members. The data were collected using Android smartphones with the SurveyCTO mobile data platform. The community survey addressed community water points and their functionality, management, benefits of functional water points to the community, the impact of natural disasters on functionality, activities linked to water during the last two years, and the main areas for perceived improvement needed from water points. The WaSH committee survey included information on WaSH committees in the program area, technical and management aspects of water points and their functionality, seasonality and drying out of water points, payment of water, as well as activities linked to water during the last two years. The functionality of water points at the time of the survey was defined as follows: (i) fully functional were water points that provided services without restriction; (ii) partially functional were water points that were defective but it is still functional in some aspects; (iii) not working were water points that had stopped providing service due to defects, but that could be functional after maintenance; (iv) abandoned were water points that were neither functional nor considered for maintenance due to feasibility issues (i.e., no service after maintenance expected, high cost for maintenance).

Informed consent was obtained from each participating community and WaSHCo member. Ethical clearance was obtained from the Institutional Review Board of the College of Health Science at Jimma University, Ethiopia (RPGC/967/2016) and the University of North Carolina at Chapel Hill (study \#15-3317).

\subsection{Data Analysis}

The statistical analysis aimed to identify community characteristics and management practices associated with functionality of water points and explore opportunities to improve water point functionality and monitoring in rural Ethiopia.

The datasets from the two surveys (community survey; WaSH committee survey) were analyzed independently, because the unique identifying code generated for each survey were not comparable 
and the unique community names were corrupted and lost for the community survey. The analysis goals were the same for each survey, since both aimed at investigating factors associated with functional community water points and identifying potential areas of improvement in terms of practitioner response to functionality and functionality monitoring.

Descriptive statistics were calculated and included frequencies for all variables of interest, as well as means, medians, maxima and minima for numerical variables.

Bivariate analyses were conducted on the WaSH committee survey to examine the strength of association between the predictor independent variables and the primary outcome variable (water point functionality). In the bivariate analysis, differences in communities in intervention and control areas were controlled for. A $90 \%$ confidence interval (CI) was used to estimate the precision of the odds ratios (OR) (significance level set at $p$-value $\leq 0.10$ ). All analysis was conducted using STATA 15 (StataCorp LLC, College Station, TX, USA).

\section{Results}

\subsection{Functionality of Water Points in Rural Ethiopia: Findings from the Community Survey}

\subsubsection{Characteristics of Communities}

The 74 communities had on average 842 households and a population of 2611 people, as shown in Table 1. A farmers' cooperative was present in $47 \%$ of the communities. Sixty-eight percent of communities had received a community-led total sanitation (CLTS) intervention. CLTS was implemented between 2000 and 2009, with the majority of CLTS interventions occurring in 2007. All interviewees were aware of the meaning of the open defecation free (ODF) community locution. More than $80 \%$ of communities were certified as open defecation free.

Table 1. Characterization of communities.

\begin{tabular}{|c|c|c|}
\hline Community Characteristics & $n$ & $\%$ \\
\hline \multicolumn{3}{|l|}{ Region } \\
\hline Amhara & 23 & 30.67 \\
\hline Oromia & 9 & 12.00 \\
\hline SNNPR * & 29 & 38.67 \\
\hline Tigray & 14 & 18.67 \\
\hline \multicolumn{3}{|l|}{ Total number of households } \\
\hline $\mathrm{N}$ & \multicolumn{2}{|c|}{74} \\
\hline Mean & \multicolumn{2}{|c|}{842} \\
\hline Median & \multicolumn{2}{|c|}{220} \\
\hline \multicolumn{3}{|l|}{ Total population } \\
\hline $\mathrm{N}$ & \multicolumn{2}{|c|}{74} \\
\hline Mean & \multicolumn{2}{|c|}{2611} \\
\hline Median & \multicolumn{2}{|c|}{1150} \\
\hline \multicolumn{3}{|c|}{ Area was affected by natural disaster in past 1 year } \\
\hline Drought & 26 & 60.47 \\
\hline Excessive rain & 17 & 39.53 \\
\hline Flood & 19 & 44.19 \\
\hline Crop failure & 30 & 69.77 \\
\hline Crop pests/diseases & 32 & 74.42 \\
\hline Disease outbreak in animals & 34 & 79.07 \\
\hline A farmers' cooperation is present & 35 & 47.30 \\
\hline \multicolumn{3}{|l|}{ Year of community-led total sanitation (CLTS) } \\
\hline $\mathrm{N}$ & \multicolumn{2}{|c|}{50} \\
\hline Mean & \multicolumn{2}{|c|}{2007} \\
\hline Median & \multicolumn{2}{|c|}{2007} \\
\hline Awareness of meaning of $\mathrm{ODF}^{* *}$ community & 58 & 78.38 \\
\hline Community has received a certificate as ODF & 29 & 39.00 \\
\hline
\end{tabular}


Most community areas had been affected by natural disasters in the year preceding the survey. Drought $(66 \%)$ was most common. Many communities also experienced excessive rain $(41 \%)$ and floods (39\%).

\subsubsection{Water Point Functionality and Management}

Communities had an average of four improved public/community water points, as shown in Table 2. On average, three were functional per community. Besides the improved water points, the communities possessed two unimproved public water points on average.

Table 2. Number of water points in communities.

\begin{tabular}{cccccc}
\hline \multicolumn{6}{c}{ Number of Water Points in Communities $(\boldsymbol{n}=\mathbf{7 4})}$. \\
\hline Variable & $\boldsymbol{n}$ & Min & Max & Mean & Median \\
\hline Total improved & 74 & 0 & 40 & 4 & 2 \\
Total functional & 74 & 0 & 25 & 3 & 1 \\
Total unimproved & 74 & 0 & 15 & 2 & 2 \\
\hline
\end{tabular}

The water points were constructed and commissioned between 2000 and 2012, as shown in Figure 1, most between 2005 and 2009.

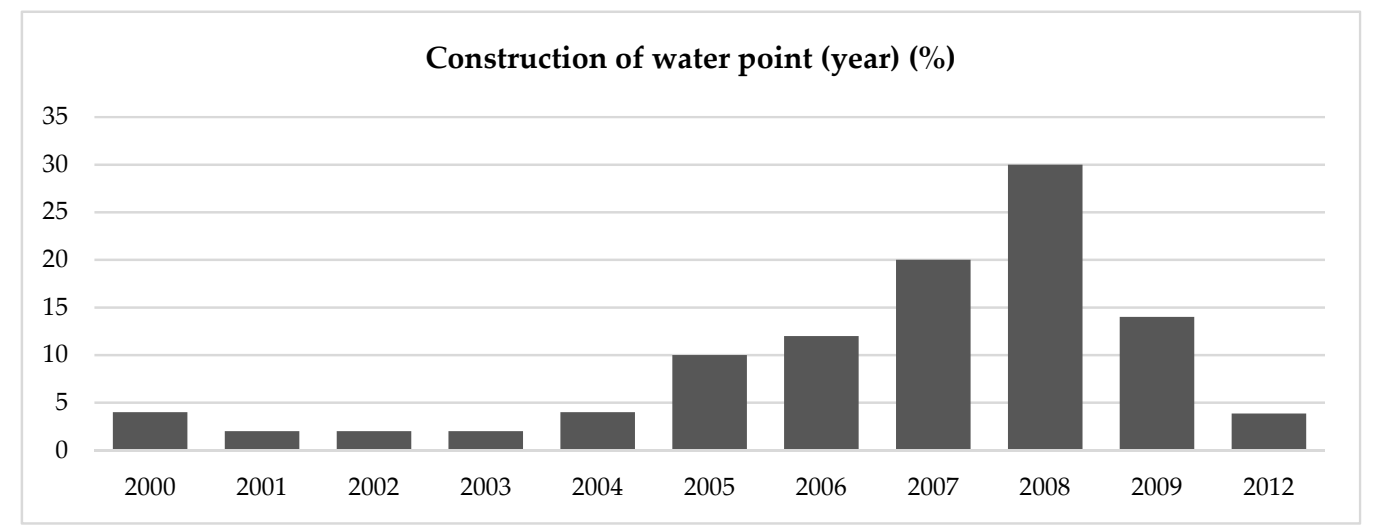

Figure 1. Construction of water point and start of functioning.

Of all water points, $65 \%$ were functional, as shown in Table 3. Most communities reported having an operational WaSH committee (88\%).

Table 3. Functionality and management of water points in intervention and control communities.

\begin{tabular}{lcc}
\hline \multicolumn{1}{c}{ Characteristics of Community } & $n$ & \% \\
\hline Total functional water points & 206 & 65.19 \\
WaSH committee is currently operational & 52 & 88.14 \\
WaSH committee manages the water point & 59 & 79.73 \\
Problems with water point solved quickly & 16 & 21.62 \\
\hline Perceived quality of management & & \\
$\quad$ Very good & 18 & 24.32 \\
$\quad$ Reasonable & 39 & 52.70 \\
$\quad$ Bad & 17 & 22.97 \\
\hline Changes in the community due to new water point & & \\
$\quad$ More time for other economic activities $(n=3)$ & 3 & 40.00 \\
$\quad$ Better health $(n=3)$ & 3 & 60.00 \\
Less diarrhea $(n=3)$ & 3 & 60.00 \\
$\quad$ More children go to school $(n=3)$ & 3 & 60.00 \\
\hline
\end{tabular}


The majority of water points were managed through WaSH committees $(80 \%)$. Community leaders, woreda or kebele administrators were rarely the ones managing the water point in the program area, as shown in Figure 2.

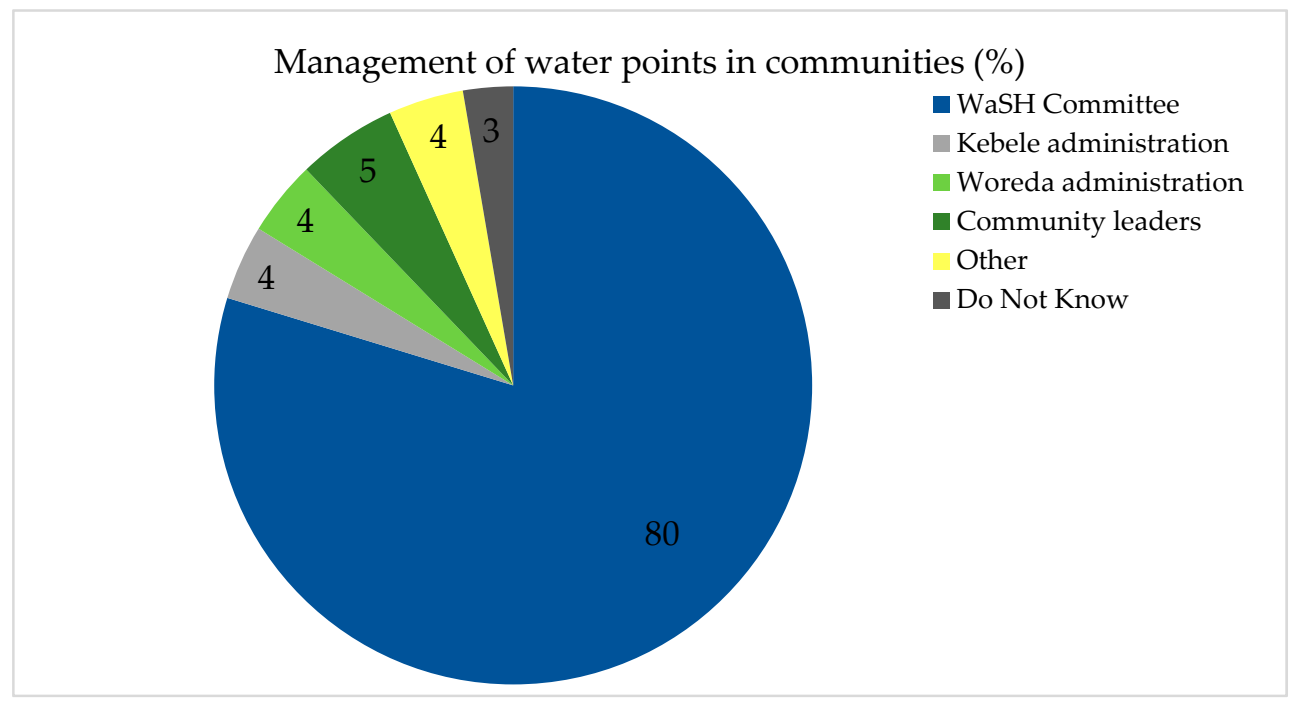

Figure 2. Management of water points in communities.

Most respondents considered the quality of management of water points reasonable (53\%), as shown in Table 3. Twenty-two percent reported problems with the water point to be solved quickly (22\%).

Most communities reported benefits as a consequence of the UNICEF intervention between 2011 and 2015 (77\%). Benefits mentioned arising from a new water point included improved health, reduced incidence of diarrhea, more time for economic activities, and more children going to school.

Numerous activities linked to water were conducted in the communities in the two years preceding the survey, as shown in Figure 3. In about half of all communities, community orientation and training had been conducted (51\%) and slightly less than a third established WaSH committees accompanied by training (28\%).

Activities linked to water conducted in communities in the last two years (\%)

Community orientation

WaSHCo establishment and training

Identification of water point type to construct

Identification of location for water point construction

Community participation and involvement Assessment of water source and technology options

Transportation, collection of water supply materials Rehabilitation of water supply system

Construction of water supply system

Water point / system abandoned / closed Inauguration of water system

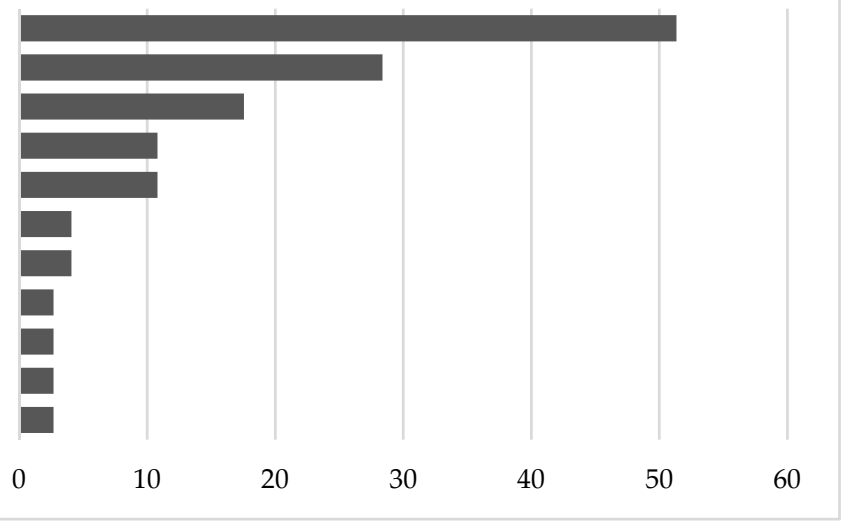

Figure 3. Activities linked to water in communities.

\subsubsection{Perceived Areas for Improvement Needed in Water Management Systems}

Community respondents reported several perceived areas for improvement of water management systems needed, as shown in Figure 4. The improvement of water quality was most prevalent in 
$61 \%$ of the communities. The distance to the water point and the supply time (53\% each) were issues that more than half of the communities wanted to improve. The improvement of water pressure was important to $47 \%$ of communities. Reacting faster to problems (41\%), the long idle time (37\%), and the long time for water collection (34\%) were also reported by communities as perceived needs.

\section{Main perceived areas for improvement needed from water management systems}

(\%)

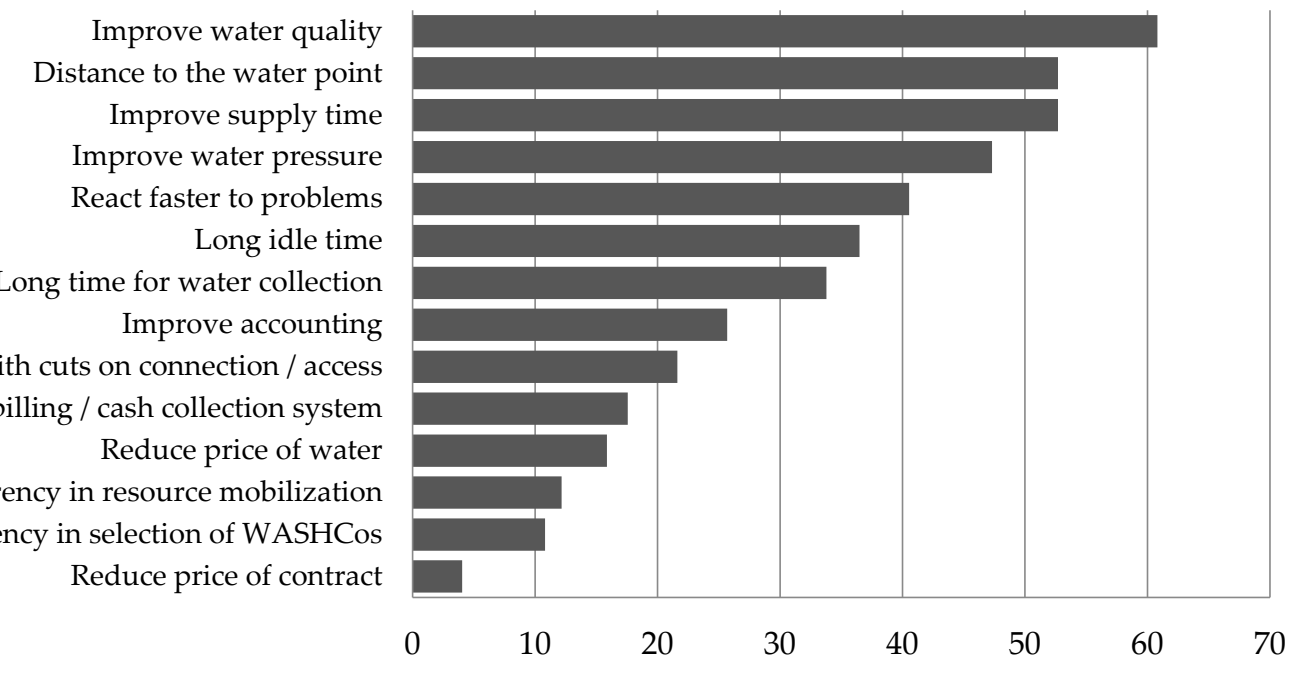

Figure 4. Perceived areas for improvement needed in communities.

\subsection{Functionality of Water Points in Rural Ethiopia: Findings from the WaSH Committee Survey}

\subsubsection{Characteristics of WaSH Committees}

WaSH committees existed in all surveyed intervention areas and in $89 \%$ of the control areas. WaSH committees in intervention communities had different characteristics to those in control communities, as shown in Table 4. The WaSH committees in the intervention areas had been established between 1988 and 2008, the committees in the control area were established between 1997 and 2012, as shown in Table 4. The vast majority of WaSHCos were operational (98\% in intervention areas; $94 \%$ in control areas). Almost half of the WaSH committees were responsible for other water points in the community (48\% in intervention areas; $42 \%$ in control areas). On average, in both areas, WaSHCos were responsible for the management of three water points.

Table 4. Characterization of WaSHCos in intervention and control areas.

\begin{tabular}{|c|c|c|c|c|}
\hline \multirow{2}{*}{ Characteristics of WaSH Committees } & \multicolumn{2}{|c|}{ Control Areas } & \multicolumn{2}{|c|}{ Intervention Areas } \\
\hline & $n$ & $\%$ & $n$ & $\%$ \\
\hline WaSH Committee exists & 31 & 88.57 & 40 & 100.00 \\
\hline WaSHCo operational/working at present & 29 & 93.55 & 39 & 97.50 \\
\hline WaSHCo responsible for other water points & 13 & 41.94 & 19 & 47.50 \\
\hline \multicolumn{5}{|l|}{ Number of water points WaSHCo manages } \\
\hline $\mathrm{N}$ & \multicolumn{2}{|c|}{13} & \multicolumn{2}{|c|}{19} \\
\hline Mean & \multicolumn{2}{|c|}{3} & \multicolumn{2}{|c|}{3} \\
\hline Median & \multicolumn{2}{|c|}{1} & \multicolumn{2}{|c|}{2} \\
\hline
\end{tabular}

\subsubsection{Water Points, Management, and Functionality}

Protected dug wells (30\% in intervention areas; $31 \%$ in control areas) and boreholes (30\% in intervention areas; $23 \%$ in control areas) were the most frequently used public water points according 
to the WaSHCo survey. A protected spring was used by $15 \%$ of the communities in the intervention areas and $23 \%$ of the communities in the control areas, as shown in Table 5 . The most used improved public water point (dug wells and boreholes) had an average depth of $50 \mathrm{~m}$ in intervention areas, and $19 \mathrm{~m}$ in the control areas.

Table 5. Characterization of water points in intervention and control communities.

\begin{tabular}{|c|c|c|c|c|}
\hline \multirow[b]{2}{*}{ Characteristics of Water Point } & \multicolumn{2}{|c|}{ Control Areas } & \multicolumn{2}{|c|}{ Intervention Areas } \\
\hline & $n$ & $\%$ & $n$ & $\%$ \\
\hline \multicolumn{5}{|c|}{ Type of public water point mostly used in community } \\
\hline Piped into dwelling & 0 & 0.00 & 1 & 2.50 \\
\hline Piped into yard/plot/compound & 1 & 2.86 & 0 & 0.00 \\
\hline Public tap/standpipe & 6 & 17.14 & 5 & 12.50 \\
\hline Tube well/borehole & 8 & 22.86 & 12 & 30.00 \\
\hline Protected well & 11 & 31.43 & 12 & 30.00 \\
\hline Protected spring & 8 & 22.86 & 6 & 15.00 \\
\hline Unprotected spring & 0 & 0.00 & 2 & 5.00 \\
\hline River/lake/pond/stream/dam & 1 & 2.86 & 2 & 5.00 \\
\hline \multicolumn{5}{|c|}{ Depth of improved water point (most used public) [meters] } \\
\hline $\mathrm{N}$ & \multicolumn{2}{|c|}{23} & \multicolumn{2}{|c|}{29} \\
\hline Mean & \multicolumn{2}{|c|}{19} & \multicolumn{2}{|c|}{50} \\
\hline Range [min-max] & \multicolumn{2}{|c|}{$1-70$} & \multicolumn{2}{|c|}{$1-282$} \\
\hline \multicolumn{5}{|l|}{ Current state of the water point } \\
\hline Working & 26 & 74.29 & 34 & 85.00 \\
\hline Working partially (with problems) & 6 & 17.14 & 3 & 7.50 \\
\hline Not working & 3 & 8.57 & 3 & 7.50 \\
\hline \multicolumn{5}{|l|}{ Reason why water point only works partially } \\
\hline Water point is dry at the moment & 2 & 22.22 & 2 & 33.33 \\
\hline One spare part is missing & 5 & 55.56 & 3 & 50.00 \\
\hline Requires a big rehabilitation & 5 & 55.56 & 2 & 33.33 \\
\hline The rehabilitation is in process & 1 & 11.11 & 1 & 16.67 \\
\hline The pump was stolen & 2 & 22.22 & 0 & 0.00 \\
\hline Abandoned & 2 & 22.22 & 1 & 16.67 \\
\hline Water point has a pump & 20 & 57.14 & 27 & 67.50 \\
\hline \multicolumn{5}{|l|}{ Type of pump } \\
\hline Afridev & 11 & 55.00 & 19 & 70.37 \\
\hline India Mark (Im-I\&Ii) & 5 & 25.00 & 3 & 11.11 \\
\hline Direct action hand pump & 1 & 5.00 & 1 & 3.70 \\
\hline Rope pump & 0 & 0.00 & 1 & 3.70 \\
\hline Submersible electrical pump & 1 & 5.00 & 2 & 7.41 \\
\hline Other hand pump & 2 & 10.00 & 1 & 3.70 \\
\hline \multicolumn{5}{|l|}{ Time to repair pump last time it broke down [days] } \\
\hline $\mathrm{N}$ & \multicolumn{2}{|c|}{20} & \multicolumn{2}{|c|}{27} \\
\hline Mean & \multicolumn{2}{|c|}{25} & \multicolumn{2}{|c|}{35} \\
\hline Median & \multicolumn{2}{|c|}{4} & \multicolumn{2}{|c|}{3} \\
\hline \multicolumn{5}{|l|}{ Perceived water quality at this water point } \\
\hline Very Bad & 2 & 5.71 & 3 & 7.50 \\
\hline Bad & 6 & 17.14 & 6 & 15.00 \\
\hline Good & 18 & 51.43 & 24 & 60.00 \\
\hline Very Good & 8 & 22.86 & 7 & 17.50 \\
\hline Do Not Know & 1 & 2.86 & 0 & 0.00 \\
\hline Water point dries up & 7 & 20.00 & 9 & 22.50 \\
\hline
\end{tabular}

Figure 5 shows an association of well depth and water availability. The association between well depth and drying out of water points, however, was not found statistically significant. 
About $80 \%$ of all water points were fully functional (85\% in intervention areas; $74 \%$ in control areas), some were partially functional ( $8 \%$ in intervention areas; $17 \%$ in control areas), $8 \%$ were not working at all. Reasons for water points only working partially included missing spare parts (53\%), need for rehabilitation (33\% in intervention areas; $56 \%$ in control areas), water point being dry (33\% in intervention areas; $22 \%$ in control areas) or abandoned (17\% in intervention areas; $22 \%$ in control areas). Other reasons for water points functioning only partially were ongoing rehabilitation (14\%), or water pump having been stolen (none in intervention areas; $22 \%$ in control areas).

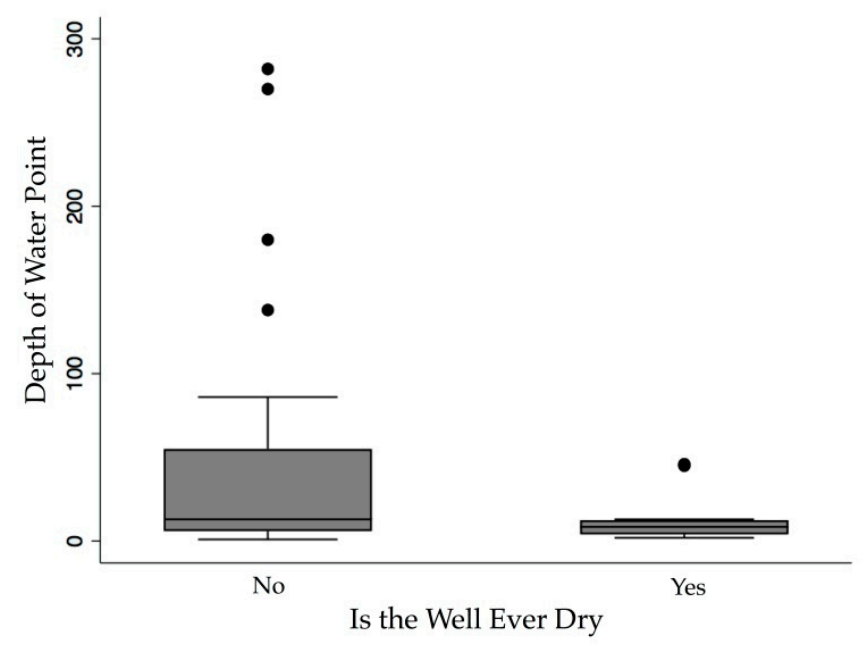

Figure 5. Well depth and drying up of water point.

About two thirds of all water points had a pump (68\% in intervention areas; $57 \%$ in control areas). Afridev pumps were most common (70\% in intervention areas; $55 \%$ in control areas), fewer communities used an India Mark (11\% in intervention areas; 25\% in control areas) or other pumps.

WaSH committees were mainly responsible for the maintenance and repair of pumps in the intervention (85\%) and control (75\%) areas. Woreda water offices also took care of maintenance and repairs of pumps (41\% in intervention areas; $60 \%$ in control areas). In the intervention area, five percent of water pumps were managed by regional water offices, as shown in Table 6.

Table 6. Responsibility of maintenance and repair of pump.

\begin{tabular}{ccc}
\hline & Control Areas $(\boldsymbol{n}=\mathbf{4 3})$ & Intervention Areas $(n=30)$ \\
\hline WaSH committee & 75 & 85 \\
Woreda water office & 60 & 41 \\
Regional water office & 0 & 5 \\
\hline
\end{tabular}

The last time the pump broke down, pump repairs took on average 35 days in the intervention area communities and 25 days in the control area communities, as shown in Table 5.

The majority of the communities perceived the water quality at the water point as good $(60 \%$ in intervention areas; $51 \%$ in control areas), or very good (18\% in intervention areas; $23 \%$ in control areas).

Out of all communities, 21\% reported their water point dries up at some point of the year.

Payment collection for water was similar in the dry and in the rainy seasons, as shown in Table 7. Most communities had WaSH committees that did not collect payment (dry season: 40\% in intervention areas; $56 \%$ in control areas; rainy season: $45 \%$ in intervention areas; $57 \%$ in control areas).

In more than half of all communities, community orientation and training had been conducted (60\% in intervention areas; $52 \%$ in control areas). Water point types to be constructed were identified and selected by $43 \%$ of the intervention and $30 \%$ of the control communities. About $28 \%$ established and trained a WaSH committee, slightly less mentioned community participation and involvement, 
including community contributions in form of cash, labor, and kind (25\%). In the intervention area, more activities linked to water were conducted than in the control area, as shown in Figure 6.

Table 7. Seasonal payment for water.

\begin{tabular}{lcccc}
\hline & \multicolumn{2}{c}{ Control Areas } & \multicolumn{2}{c}{ Intervention Areas } \\
\hline \multicolumn{1}{c}{ Seasonal Payment of Water } & $\mathbf{N}$ & $\mathbf{\%}$ & $\mathbf{N}$ & $\mathbf{\%}$ \\
\hline Payments collection in dry season & & & & \\
$\quad$ There is no payment & 16 & 45.71 & 16 & 40.00 \\
Per Jeri-can of 20 L & 4 & 11.43 & 8 & 20.00 \\
Regularly per month & 10 & 28.57 & 9 & 22.50 \\
Per break down of water point & 0 & 0.00 & 1 & 2.50 \\
\hline Payments collection in rainy season & & & & \\
There is no payment & 20 & 57.14 & 18 & 45.00 \\
Per Jeri-can of 20 L & 4 & 11.43 & 6 & 15.00 \\
Regularly per month & 7 & 20.00 & 9 & 22.50 \\
Per break down of water point & 0 & 0.00 & 1 & 2.50 \\
\hline
\end{tabular}

Activities linked to water conducted in communities in the last two years (\%)

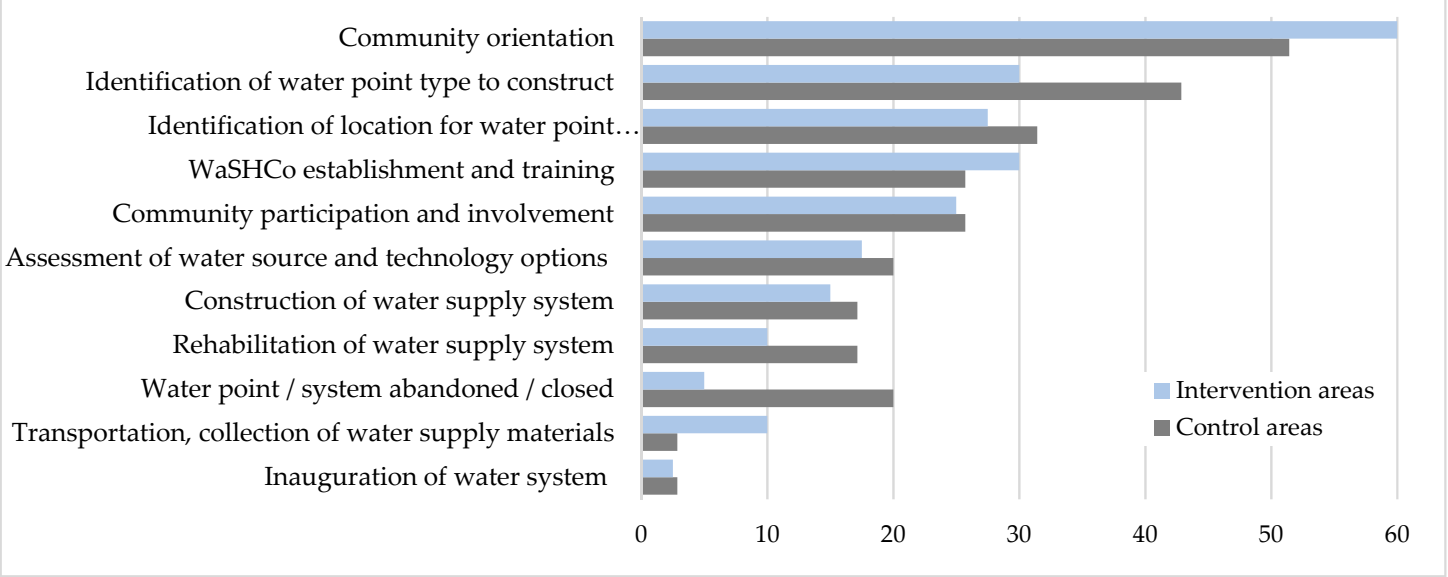

Figure 6. Activities linked to water according to WaSH committees.

Comparing the main activities linked to water conducted during the previous two years between community and WaSH committee surveys revealed that similar activities are reported for both groups at similar frequency, i.e., community orientation (about 53\%), WaSH committee establishment and training (28\%), inauguration of water system (3\%). However, differences in reporting become visible for other activities, as shown in Figures 3 and 6.

There were substantive differences in the identification of water point types ( $18 \%$ community leaders versus $36 \%$ WaSHCo members) and locations where to construct these (11\% community leaders versus $30 \%$ WaSHCo members), the assessment of water source and technology options ( $4 \%$ community leaders versus $19 \%$ WaSHCo members), the construction ( $3 \%$ community leaders versus $16 \%$ WaSHCo members), rehabilitation (3\% community leaders versus $13 \%$ WaSHCo members), and abandonment ( $3 \%$ community leaders versus $13 \%$ WaSHCo members) of water supply systems, as well as community participation and involvement (11\% communities, $25 \%$ WaSH committees).

\subsubsection{Factors Associated with the Functionality of Water Points}

In bivariate analyses of the WaSHCo survey, the functionality of water points (working at the time of the survey) was significantly associated with characteristics of the water point, such as the drying up of the water point, as shown in Table 8. The drying up of the water point significantly reduced the functionality compared to water points that never dry up, both in the unadjusted (OR 0.33; 
CI 0.09-1.13; $p=0.077$ ) and in the adjusted model (OR 0.28; CI 0.08-0.99; $p=0.050$ ). A water point that was an Indian mark pump was significantly more likely to be functional as compared to any other pump (OR 3.55; CI 0.92-13.74; $p=0.067$ ) in the unadjusted model. The functionality of the water point was also significantly associated with the year in which the WaSHCo was created. Water points in areas with more recently created WaSHCos had significantly reduced odds of functionality (OR 0.83 ; CI $0.69-1.02 ; p=0.072$ ) in the unadjusted model, and so did having carried out an assessment of water source and technology options in the past two years as compared to those who did not conduct such an activity (OR 0.19; CI 0.06-0.68; $p=0.010$ ).

Table 8. Bivariate logistic regression results for the use of basic water services.

\begin{tabular}{|c|c|c|c|c|c|c|c|c|}
\hline \multirow{3}{*}{ Bivariate Analysis; Outcome is Functionality } & \multicolumn{4}{|c|}{ Unadjusted Model } & \multicolumn{4}{|c|}{ Adjusted Model } \\
\hline & \multicolumn{4}{|c|}{ CI $90 \%$} & \multicolumn{4}{|c|}{ CI $90 \%$} \\
\hline & OR & Low & Up & $p$-Value & OR & Low & Up & $p$-Value \\
\hline \multicolumn{9}{|l|}{ Explanatory variable } \\
\hline \multicolumn{9}{|l|}{ Characteristics of water points } \\
\hline Number of private improved water points & 1.24 & 0.24 & 6.38 & 0.801 & 0.98 & 0.18 & 5.28 & 0.980 \\
\hline Number of public improved water points & 0.90 & 0.74 & 1.08 & 0.253 & 0.95 & 0.78 & 1.17 & 0.632 \\
\hline Depth of the improved water point $[\mathrm{m}]$ & 1.01 & 0.99 & 1.04 & 0.316 & 1.01 & 0.99 & 1.04 & 0.391 \\
\hline Water point ever dries up & 0.33 & 0.10 & 1.13 & $0.077^{*}$ & 0.28 & 0.08 & 1.00 & 0.050 \\
\hline Water point has a pump & \multicolumn{4}{|c|}{ Omitted } & 2.16 & 0.68 & 6.90 & 0.192 \\
\hline Indian mark pump & 3.55 & 0.92 & 13.74 & 0.067 & 3.03 & 0.76 & 11.99 & 0.115 \\
\hline \multicolumn{9}{|l|}{ Management of water points } \\
\hline Year in which water point was constructed & 1.00 & 1.00 & 1.00 & 0.443 & 1.00 & 1.00 & 1.00 & 0.527 \\
\hline Water point constructed by local micro-enterprise & 1.10 & 0.34 & 3.60 & 0.875 & 0.93 & 0.28 & 3.15 & 0.911 \\
\hline Water point constructed by Woreda water office & 0.50 & 0.16 & 1.53 & 0.224 & 0.62 & 0.19 & 1.98 & 0.417 \\
\hline \multicolumn{9}{|l|}{ Responsibility for maintenance of pump } \\
\hline WaSHCo/caretakers & 2.83 & 0.55 & 14.69 & 0.216 & 1.57 & 0.24 & 10.50 & 0.641 \\
\hline Year in which WaSHCo was created & 0.83 & 0.69 & 1.02 & 0.072 & 0.89 & 0.73 & 1.09 & 0.261 \\
\hline Woreda water office maintenance of the pump & 0.27 & 0.05 & 1.52 & 0.138 & 0.40 & 0.07 & 2.42 & 0.317 \\
\hline WaSHCo responsible for other water points & 0.81 & 0.27 & 2.45 & 0.705 & 0.88 & 0.27 & 2.80 & 0.823 \\
\hline Number of males on the WaSHCo & 1.13 & 0.77 & 1.67 & 0.530 & 1.10 & 0.74 & 1.64 & 0.647 \\
\hline Number of females on the WaSHCo & 0.83 & 0.48 & 1.41 & 0.483 & 0.81 & 0.46 & 1.44 & 0.473 \\
\hline Maintenance/caregiver group for water point & 0.36 & 0.11 & 1.13 & 0.081 & 0.39 & 0.12 & 1.27 & 0.116 \\
\hline Number of times the WaSHCo met in past year & 1.03 & 0.89 & 1.19 & 0.693 & 1.04 & 0.85 & 1.29 & 0.687 \\
\hline \multicolumn{9}{|l|}{ Water payments collection in dry season } \\
\hline No water payment & 0.67 & 0.22 & 2.02 & 0.473 & 0.60 & 0.19 & 1.89 & 0.384 \\
\hline Payment per Jeri-can of $20 \mathrm{~L}$ & 1.40 & 0.27 & 7.14 & 0.686 & 1.17 & 0.22 & 6.15 & 0.852 \\
\hline Payment regularly per month & 0.73 & 0.22 & 2.45 & 0.615 & 0.97 & 0.26 & 3.54 & 0.958 \\
\hline \multicolumn{9}{|l|}{ Water payments collection in rainy season } \\
\hline No water payment & 1.00 & 0.33 & 3.01 & 1.000 & 0.95 & 0.30 & 2.99 & 0.926 \\
\hline Payment per Jeri-can of $20 \mathrm{~L}$ & 1.08 & 0.21 & 5.65 & 0.930 & 0.95 & 0.18 & 5.10 & 0.951 \\
\hline Payment regularly per month & 0.55 & 0.16 & 1.89 & 0.342 & 0.67 & 0.18 & 2.50 & 0.545 \\
\hline \multicolumn{9}{|l|}{ Activities related to water } \\
\hline Community orientation & 1.80 & 0.59 & 5.48 & 0.301 & 1.53 & 0.48 & 4.81 & 0.472 \\
\hline Identification of water point type to construct & 1.27 & 0.39 & 4.15 & 0.688 & 1.28 & 0.38 & 4.332 & 0.690 \\
\hline Identification of location for point construction & 0.66 & 0.21 & 2.10 & 0.480 & 0.81 & 0.24 & 2.762 & 0.740 \\
\hline Assessment of water source/technology options & 0.20 & 0.06 & 0.68 & 0.010 & 0.23 & 0.06 & 0.835 & 0.025 \\
\hline Community participation and involvement & 0.67 & 0.20 & 2.26 & 0.517 & 0.61 & 0.18 & 2.100 & 0.430 \\
\hline Construction of water supply system & 0.77 & 0.18 & 3.23 & 0.715 & 0.72 & 0.17 & 3.116 & 0.661 \\
\hline Rehabilitation of water supply system & 0.57 & 0.13 & 2.52 & 0.461 & 0.58 & 0.13 & 2.608 & 0.474 \\
\hline WaSHCo establishment and training & 0.87 & 0.26 & 2.88 & 0.819 & 1.05 & 0.29 & 3.805 & 0.941 \\
\hline Water point/system abandoned/closed & 0.93 & 0.17 & 4.95 & 0.927 & 1.08 & 0.19 & 6.127 & 0.930 \\
\hline Transportation/collection of supply materials & 0.37 & 0.06 & 2.42 & 0.298 & 0.26 & 0.04 & 1.860 & 0.179 \\
\hline Celebration/inauguration of supply system & 0.25 & 0.012 & 4.31 & 0.343 & 0.24 & 0.01 & 4.149 & 0.323 \\
\hline Other activities & 0.67 & 0.16 & 2.87 & 0.586 & 0.65 & 0.15 & 2.859 & 0.567 \\
\hline
\end{tabular}

Note: ${ }^{*}$ Significant factors marked in bold. The significance level was set at $p$-value $\leq 0.10$. 


\section{Discussion}

We analyzed community and WaSH committee survey data on water point functionality and management from a UNICEF program evaluation in four regions of Ethiopia. We found that most water points were protected dug wells and boreholes, and $80 \%$ of water points were functional at the time of survey. Eighty percent of communities had a WaSH committee, nearly all were operational, and were primarily responsible for repairs. Repair times were slow-on average, taking more than a month. India Mark II pumps were more likely to be functional than other pump types and communities with longer-established WaSH committees had higher water point functionality compared to WaSH committees that were established more recently. Communities suggested that the most important water system improvement opportunities were improving water quality and water pressure, reducing distance to sources, and speeding up repair times.

\subsection{Factors Associated with the Functionality of Water Points}

Factors associated with water point functionality are multidimensional, and include the materials used to build the water points, fee collection, access to post-construction support, and management arrangements [13-19]. Our study indicated that water points constructed with Indian mark pumps were significantly more likely to be functional than other types, regardless of intervention or control area. This contradicts previous studies from other countries noting that Indian mark pumps are less functional compared with Nira hand pumps [13]. The reason for higher functionality of water points with India Mark pumps cannot be determined based on our data. Follow up studies with larger sample sizes could uncover whether the level of training on maintenance and repair, or the amount of spare parts could have been higher for this particular type of water point. Another factor affecting water point functionality is management. In Ethiopia, water points are mainly managed through WaSH committees. In the program area, most WaSHCos (88\%) actively take care of water management systems. This study has pointed out that water points managed by longer-established WaSHCos are more functional than those managed by younger committees. Longer-established committees may have better management structures in place, better training, and more motivated and committed members. These considerations may suggest that regularly training existing water committees may be viable solutions for improving the functionality of water points.

Considering that most water points were managed by WaSHCos, their empowerment and empowerment of the community is crucial for a better and for more sustainable water services [20]. We found that community participation and involvement was low overall, with few communities engaged in the assessment of water sources and technology options, training of WaSH committees, and other engagement activities. Participation, empowerment, and sense of ownership have been linked as important factors that contribute to water system sustainability in other studies. Not all forms of participation contribute to sustainability equally-participation in 'software' activities such as finances and management are associated with higher levels of sustainability whereas community participation in technical decisions can negatively affect sustainability [21]. Nevertheless, programs should consult and engage communities in the water system installation and management processes to create a stronger sense of ownership so that communities are committed to their systems.

\subsection{Droughts, Extreme Weather Events, and Vulnerability of Water Points}

In the program area, about $20 \%$ of the communities reported that their water points dry up at some point of the year which contributes to lower water service availability. Considering that most communities are affected by droughts, which are projected to become more frequent and severe, this paints a gloomy picture in terms of access to drinking water.

Deeper wells increase community resilience and water access in the context of drought, as shown in Figure 5. The Ministry of Water, Irrigation and Energy (MoWIE) provides deeper boreholes and larger piped systems that connect several communities through their Climate Resilient WaSH Strategy 
and OneWaSH program, which maps deep groundwater resources and drills for more sustainable water supplies [22,23]. The appropriateness of deep groundwater investigation and development during periods of increased drought in Ethiopia has been demonstrated before. Investments in deeper groundwater prove to reduce the unit costs and improve the sustainability of water points [24-27]. Similarly, mapping of water points, year-round availability of water, and vulnerability towards droughts provide opportunities for monitoring and water service delivery in rural areas $[28,29]$.

Besides droughts, excessive rains and floods are common in the program area (41\% reported excessive rains, $39 \%$ floods). All these extreme weather event types generate additional cost for water. We found no significant association between excessive rain or floods and water point functionality, possibly due to small sample size and low study power, which did not allow sophisticated analyses. Extreme weather events should however be taken into account in order to assess the vulnerability, improve the monitoring, and adapt the functionality of water points towards climate resilient WaSH $[22,30]$.

Recognizing the limitations of voluntary WaSH committees [31], particularly for larger more climate-resilient multi-village schemes, the MoWIE in partnership with UNICEF have developed a model for semi-professional rural utilities that aim to group several water systems together under one management team. Programmatic opportunities to improve water point functionality lie in supporting the utility with the development of a business plan, setting tariffs, and ensuring regular maintenance. This model is currently being rolled out and proving successful in Somali, Afar, and Amhara regions, Ethiopia [32].

\subsection{Comparing Findings in Intervention and Control Area}

The comparison of the different respondent groups' answers on water management activities in the program area suggests: WaSH committee members, as focal points for water management, possess more detailed knowledge on the activities that are being carried out than community leaders who are also responsible for many other issues in the community.

Comparing the main activities linked to water conducted during the previous two years between WaSH committees of intervention and control group surprisingly reveals that more activities were done in the control group. The WaSH intervention took place between 2011 and 2015, and most of the activities named in Figure 6 were part of it. The evaluation took place two years after the finalization of the UNICEF program, in 2017. This may speak to limited new activities having been conducted since the end of the project. Less activities in the intervention group could, however, also be owed to having 'nice new' WaSH systems implemented through the intervention, and thus no urgent need for further activities.

Considering that water points are mostly managed by WaSHCos, this may indicate that for improved water point functionality, more care is needed by the implementing agencies in handing over activities to the respective WaSHCos, to build capacity by enabling them to (better and sustainably) conduct water management activities after the finalization of projects [21]. This is supported by previous studies that found water systems managed by the community or semi-professionalized providers to not only be less costly, but also more sustainable [26].

\subsection{Opportunities to Improve Water Point Functionality Monitoring}

There are several opportunities to improve and use the survey questions from this program evaluation in monitoring of water points. Collection of more detailed data on seasonal variation and management is important to inform water services throughout the year and to better understand changes due to extreme weather events. While the survey included questions on seasonal payment, several others need to be included such as seasonal water point management [30].

The most common reason for water points to be partially functional was missing spare parts $(53 \%)$. This is consistent with previous studies, where parts required for repair [33]. This underlines the importance of understanding what parts commonly break or are lost or stolen from water points, 
to ensure that local post-construction support providers have the parts they need and local supplies have parts in stock for purchase. Improving the questions posed to WaSH committee members on types of part breakdown would provide information to decision makers and private sector actors on how to stock spare parts suppliers and improve supply chains.

Ensuring that questions are policy and program relevant, evidence based, and technically sound (i.e., follow SMART criteria) ensure useful data collection in the future. Some questions in the survey could be improved, such as identifying "adequate" sites for construction.

Actors conducting surveys may add implementation and process indicators to understand the processes by which water points remain functional over time. This would enable the use of monitoring data in operational and implementation research to understand the processes that drive improvement. An example would be the hardware and management pathways associated with water point rehabilitation when systems break down [34].

\subsection{Closing the Knowledge to Action Gap}

This study identified the main perceived areas for improvement in water management systems that community leaders deemed important, as shown in Figure 4 . While water quality $(60 \%)$, time and distance to water supply (53\%), water pressure $(47 \%)$, and response time to problems $(41 \%)$ were prevalent, improvements of accounting $(26 \%)$ and cash collection systems $(18 \%)$ were considered less vital. Transparency in resource mobilization $(12 \%)$ and in the selection of WaSHCos (11\%) were of minor relevance in terms of perceived importance.

Taking these community leaders' 'priority lists' into consideration offers opportunities for demand-driven, adaptive and targeted design, and implementation of rural water supply programs, which, if they include the grassroots level as key informants and actors of change, can succeed $[35,36]$. While community perceptions point to actual shortcomings, they also mirror community needs and suggest acceptable solutions [37] that will likely be supported through a sense of ownership and participation [17].

When the 'voice' of the community is not taken into account, the service quality may not improve. A study from Tanzania found that dissatisfaction among community members on water service delivery or 'negative feedback' in terms of customers refusing to pay water bills or tampering with meters encouraged decision makers to improve services [38]. Therefore, future WaSH interventions should better integrate the 'voice' of the community, the WaSH committees, and other stakeholders at different stages of the program management: in planning, monitoring, and evaluating interventions.

\subsection{Methodological Discussions and Limitations}

While the data represent water services for more than eighty communities, which have populations of 26,000 on average, there were insufficient water points to conduct multivariable regression analyses. Due to the small sample size, only descriptive statistics and bivariate analyses were performed, and these analyses were only performed with 74 observations. This did not allow for sophisticated analyses. Therefore, these findings are not per se generalizable beyond the regions studied. However, similar trends may be visible in similar settings. Community respondents may not have perfect knowledge of the water point situation in the community and some responses may not represent the true situation. The data are cross-sectional therefore only associations can be shown and not causation. Benefits of the water system as reported by communities (e.g., reduced incidence of diarrhea) were qualitatively reported and not verified.

\section{Conclusions and Policy Recommendations}

This evaluation shows that, in the four Ethiopian program regions, water point functionality is mainly associated with the type of hand pump [13]. Breakdowns were linked to missing spare parts [33], proper management [34], and droughts [30,39]. With droughts predicted to become more frequent and prolonged in Ethiopia as a consequence of climate change, more climate-resilient water 
supply schemes gain importance and provide opportunities for improved water point functionality. This study captured the perceptions on main areas of water management systems that community leaders deem important. These were improving water quality and water pressure, reducing distance to sources, and speeding up repair times. Here lies an opportunity for closing the knowledge to action gap: integrating different stakeholders in the development of a policy- and program-relevant survey design and adding implementation and process indicators to understand the processes by which water points remain functional over time, integrating them in data collection, monitoring, and evaluation processes would improve rural water supply projects overall. While community leaders' perceptions such as on perceived areas for improvement point to actual shortcomings, they also mirror community needs and recommend solutions that will likely be supported by participation at the grassroots level [37]. Therefore, transdisciplinary collaboration with an emphasis on perceptions and participation of the target communities and WaSH committees as focal points of water management, and a more "demand-driven" approach are supportive tools to make programming potentially more targeted, effective, and sustainable [35-37].

Author Contributions: A.A. and J.B. (Jamie Bartram) designed the research presented in this paper. A.A. coordinated the data collection. L.F. conducted the data analysis. C.A. was the lead author. R.C. and E.S. contributed to the writing. A.A., J.B. (Jane Bevan), S.G. and J.B. (Jamie Bartram) revised the paper.

Funding: Funding for collection and analysis of data was provided by UNICEF Ethiopia (43185731/UNC ID 5102828).

Acknowledgments: We thank Getachew Hailemichael of UNICEF Ethiopia for the coordination of the study, Georgia Kayser, Ronna Chan and Margaret (Peggy) Bentley for their support for start-up and training of the survey, and Jeanne Luh and Amy Guo, A.J. Karon, and Kate Shields for cleaning of the data and preparing the project report. Data collection would not have been possible without the collaboration and support of Argaw Ambelu's team of supervisors and enumerators from Jimma University. Finally, we thank all of the study participants who have taken time to provide the information analyzed in this study.

Conflicts of Interest: The authors declare no conflict of interest. The funders had a role in the design of the study; in the collection, analyses, or interpretation of data; in the writing of the manuscript, or in the decision to publish the results.

\section{References}

1. Bartram, J.; Lewis, K.; Lenton, R.; Wright, A. Focusing on improved water and sanitation for health. Lancet 2005, 365, 810-812. [CrossRef]

2. Bartram, J.; Cairncross, S. Hygiene, sanitation, and water: Forgotten foundations of health. PLoS Med. 2010, 7, e1000367. [CrossRef] [PubMed]

3. Bartram, J.; Godfrey, S. Drinking-water supply. In Routledge Handbook of Water and Health; Bartram, J., Baum, R., Coclanis, P.A., Gute, D.M., Kay, D., Mc Fayden, S., Pond, K., Robertson, W., Rouse, M.J., Eds.; Routledge: London, UK, 2015; pp. 191-202, ISBN 978-1138910072.

4. Black, R.E.; Morris, S.S.; Bryce, J. Where and why are 10 million children dying every year? Lancet 2003, 361, 2226-2234. [CrossRef]

5. Clasen, T.F.; Alexander, K.T.; Sinclair, D.; Boisson, S.; Peletz, R.; Chang, H.H.; Majorin, F.; Cairncross, S. Interventions to improve water quality for preventing diarrhea. Cochrane Database Syst. Rev. 2015, 10, 1-201. [CrossRef]

6. Esrey, S.A.; Potash, J.B.; Roberts, L.; Shiff, C. Effects of improved water supply and sanitation on ascariasis, diarrhoea, dracunculiasis, hookworm infection, schistosomiasis, and trachoma. Bull. WHO 1991, 69, 609-621. [PubMed]

7. Fewtrell, L.; Kaufmann, R.B.; Kay, D.; Enanoria, W.; Haller, L.; Colford, J.M., Jr. Water, sanitation, and hygiene interventions to reduce diarrhoea in less developed countries: A systematic review and meta-analysis. Lancet Inf. Dis. 2005, 5, 42-52. [CrossRef]

8. UN General Assembly, Transforming Our World: The 2030 Agenda for Sustainable Development. 21 October 2015. A/RES/70/1. Available online: http:/ /www.refworld.org/docid/57b6e3e44.html (accessed on 18 September 2018). 
9. WHO; UNICEF. Progress on Drinking Water, Sanitation and Hygiene-2015 Update and SDG Baselines 2015; United Nations Children's Fund: Geneva, Switzerland; World Health Organization: Geneva, Switzerland, 2015.

10. Federal Democratic Republic of Ethiopia. Growth and Transformation Plan II (GTP II) (2015/16-2019/20); National Planning Commission: Adis Abeba, Ethiopia, 2016.

11. Anthonj, C.; Fleming, L.; Godfrey, S.; Ambelu, A.; Bevan, J.; Cronk, R.; Bartram, J. Health risk perceptions are associated with domestic use of basic water and sanitation services-Evidence from rural Ethiopia. Int. J. Environ. Res. Public Health 2018, 15, 2112. [CrossRef] [PubMed]

12. Lee, E.L.; Schwab, K.J. Deficiencies in drinking water distribution systems in developing countries. J. Water Health 2005, 3, 109-127. [CrossRef] [PubMed]

13. Cronk, R.; Bartram, J. Factors Influencing water system functionality in Nigeria and Tanzania: A regression and Bayesian network analysis. Environ. Sci. Technol. 2017, 51, 11336-11345. [CrossRef] [PubMed]

14. Carter, R.C.; Ross, I. Beyond 'functionality' of handpump-supplied rural water services in developing countries. Waterlines 2016, 35, 94-110. [CrossRef]

15. Alexander, K.T.; Tesfaye, Y.; Dreibelbis, R.; Abaire, B.; Freeman, M.C. Governance and functionality of community water schemes in rural Ethiopia. Int. J. Public Health 2015, 60, 977-986. [CrossRef] [PubMed]

16. Foster, T. Predictors of sustainability for community-managed handpumps in sub-Saharan Africa: Evidence from Liberia, Sierra Leone, and Uganda. Environ. Sci. Technol. 2013, 47, 12037-12046. [CrossRef] [PubMed]

17. Whittington, D.; Davis, J.; Prokopy, L.; Komives, K.; Thorsten, R.; Lukacs, H.; Wakeman, W. How well is the demand-driven, community management model for rural water supply systems doing? Evidence from Bolivia, Peru and Ghana. Water Policy 2009, 11, 696-718. [CrossRef]

18. Foster, T.; Shantz, A.; Lala, S.; Willetts, J. Factors associated with operational sustainability of rural water supplies in Cambodia. Environ. Sci. Water Res. Technol. 2018, 4, 1577-1588. [CrossRef]

19. Fisher, M.B.; Shields, K.F.; Chan, T.U.; Christenson, E.; Cronk, R.D.; Leker, H.; Samani, D.; Apoya, P.; Lutz, A.; Bartram, J. Understanding handpump sustainability: Determinants of rural water source functionality in the Greater Afram Plains region of Ghana. Water Resour. Res. 2015, 51, 8431-8449. [CrossRef] [PubMed]

20. Behnke, N.; Klug, T.; Cronk, R.; Shields, K.F.; Lee, K.; Kelly, E.; Allgood, G.; Bartram, J. Resource mobilization for community-managed rural water systems: Evidence from Ghana, Kenya, and Zambia. J. Clean. Prod. 2017, 156, 437-444. [CrossRef]

21. Marks, S.J.; Davis, J. Does user participation lead to sense of ownership for rural water systems? Evidence from Kenya. World Dev. 2012, 40, 1569-1576. [CrossRef]

22. Butterworth, J. Getting to the Heart of Climate Resilient WASH. 2018. Available online: https://www. ircwash.org/blog/getting-heart-climate-resilient-wash (accessed on 18 September 2018).

23. Federal Democratic Republic of Ethiopia, Ministry of Water, Irrigation and Energy (MoWIE). Climate Resilient Water Safety Strategic Framework; Ministry of Water, Irrigation and Energy: Adis Abeba, Ethiopia, 2016.

24. Godfrey, S.; van der Velden, M.; Muianga, A.; Xavier, A.; Downs, K.; Morgan, C.; Bartram, J. Sustainability check: Five-year annual sustainability audits of the water supply and open defecation free status in the "One Million Initiative", Mozambique. Environ. Sci. Eng. 2014, 4, 471-483. [CrossRef]

25. Godfrey, S.; Hailemichael, G. Three-phase approach to improve deep groundwater supply availability in the Elidar district of Afar region of Ethiopia. J. Water Sanit. Hyg. Dev. 2016, 6, 414-424. [CrossRef]

26. Godfrey, S.; Hailmicheal, G. Life cycle cost analysis of water supply infrastructure affected by low rainfall in Ethiopia. J. Water Sanit. Hyg. Dev. 2017, 7, 601-610. [CrossRef]

27. Josephs-Afoko, D.; Godfrey, S.; Campos, L. Assessing the performance and robustness of the UNICEF model for groundwater exploration in Ethiopia through application of the analytic hierarchy process, logistic regression and artificial neural networks. Water SA J. 2018, 44, 365-376. [CrossRef]

28. Giné-Garriga, R.; Jiménez-Fernández de Palencia, A.; Pérez-Foguet, A. Water-sanitation-hygiene mapping: An improved approach for data collection at local level. Sci. Total Environ. 2013, 463-464, 700-711. [CrossRef] [PubMed]

29. Jiménez Fernández de Palencia, A.; Pérez-Foguet, A. Quality and year-round availability of water delivered by improved water points in rural Tanzania: Effects on coverage. Water Policy 2012, 14, 509-523. [CrossRef] 
30. Kelly, E.; Shields, K.F.; Cronk, R.; Lee, K.; Behnke, N.; Klug, T.; Bartram, J. Seasonality, water use and community management of water systems in rural settings: Qualitative evidence from Ghana, Kenya, and Zambia. Sci. Total Environ. 2018, 628-629, 715-721. [CrossRef] [PubMed]

31. Hutchings, P.; Chan, M.Y.; Cuadrado, L.; Ezbakhe, F.; Mesa, B.; Tamekawa, C.; Franceys, R.A. Systematic review of success factors in the community management of rural water supplies over the past 30 years. Water Policy 2015, 17, 963-983. [CrossRef]

32. Butterworth, J. Rural Utilities for Water Supply in Ethiopia. 2018. Available online: https://www.ircwash. org/blog/rural-utilities-water-supply-ethiopia (accessed on 18 September 2018).

33. Klug, T.; Cronk, R.; Shields, K.F.; Bartram, J. A categorization of water system breakdowns: Evidence from Liberia, Nigeria, Tanzania, and Uganda. Sci. Total Environ. 2018, 619, 1126-1132. [CrossRef] [PubMed]

34. Klug, T.; Shields, K.F.; Cronk, R.; Kelly, E.; Behnke, N.; Lee, K.; Bartram, J. Water system hardware and management rehabilitation: Qualitative evidence from Ghana, Kenya, and Zambia. Int. J. Hyg. Environ. Health 2017, 220, 531-538. [CrossRef] [PubMed]

35. Hering, J. Implementation science for the environment. Environ. Sci. Technol. 2018, 52, 5555-5560. [CrossRef] [PubMed]

36. Klenk, N.L.; Meehan, K. Transdisciplinary sustainability research beyond engagement models: Towards adventures in relevance. Environ. Sci. Policy 2017, 78, 27-35. [CrossRef]

37. Anthonj, C.; Diekkrüger, B.; Borgemeister, C.; Kistemann, T. Health risk perceptions and local knowledge of water-related infectious disease exposure among Kenyan wetland communities. Int. J. Hyg. Environ. Health 2018, 222, 34-48. [CrossRef] [PubMed]

38. Nganyanyuka, K.; Martinez, J.; Lungo, J.; Georgiadou, Y. If citizens protest, do water providers listen? Water woes in a Tanzanian town. Environ. Urban. 2018, 30, 613-630. [CrossRef]

39. Pearce, J. Real Time Monitoring of Boreholes Enables Critical Services to be Sustained during the Drought in Somali Region. 2017. Available online: https://www.ircwash.org/blog/real-time-monitoring-boreholesenables-critical-services-be-sustained-during-drought-somali (accessed on 18 September 2018).

(C) 2018 by the authors. Licensee MDPI, Basel, Switzerland. This article is an open access article distributed under the terms and conditions of the Creative Commons Attribution (CC BY) license (http:/ / creativecommons.org/licenses/by/4.0/). 